\title{
Mechanisms and heterogeneity of in situ mineral processing by the marine nitrogen fixer Trichodesmium revealed by single-colony metaproteomics
}

Noelle A. Held ${ }^{1,2,6}$, Kevin M. Sutherland (1D ${ }^{1,2,7}$, Eric A. Webb ${ }^{3}$, Matthew R. Mcllvin ${ }^{1}$, Natalie R. Cohen ${ }^{1}$, Alexander J. Devaux ${ }^{4}$, David A. Hutchins (D) ${ }^{3}$, John B. Waterbury ${ }^{5}$, Colleen M. Hansel (iD) and Mak A. Saito ${ }^{1}{ }^{1 凶}$

(C) The Author(s) 2021

The keystone marine nitrogen fixer Trichodesmium thrives in high-dust environments. While laboratory investigations have observed that Trichodesmium colonies can access the essential nutrient iron from dust particles, less clear are the biochemical strategies underlying particle-colony interactions in nature. Here we demonstrate that Trichodesmium colonies engage with mineral particles in the wild with distinct molecular responses. We encountered particle-laden Trichodesmium colonies at a sampling location in the Southern Caribbean Sea; microscopy and synchrotron-based imaging then demonstrated heterogeneous associations with iron oxide and iron-silicate minerals. Metaproteomic analysis of individual colonies by a new low-biomass approach revealed responses in biogeochemically relevant proteins including photosynthesis proteins and metalloproteins containing iron, nickel, copper, and zinc. The iron-storage protein ferritin was particularly enriched implying accumulation of mineral-derived iron, and multiple iron acquisition pathways including Fe(II), Fe(III), and Fe-siderophore transporters were engaged. While the particles provided key trace metals such as iron and nickel, there was also evidence that Trichodesmium was altering its strategy to confront increased superoxide production and metal exposure. Chemotaxis regulators also responded to mineral presence suggesting involvement in particle entrainment. These molecular responses are fundamental to Trichodesmium's ecological success and global biogeochemical impact, and may contribute to the leaching of particulate trace metals with implications for global iron and carbon cycling.

\section{INTRODUCTION}

Marine nitrogen fixation is a key process that stimulates primary production in the $\mathrm{N}$-depleted surface ocean, thereby influencing global carbon and nitrogen cycling [1, 2]. First observed by mariners who referred to it as "sea sawdust," the colonial cyanobacterium Trichodesmium is now recognized to be a major contributor to oceanic nitrogen fixation and therefore a crucial player in global nitrogen and carbon cycling [3,4]. Due to the high iron requirement of the nitrogenase enzyme, iron (Fe) is hypothesized to be a major control on the distribution of nitrogen fixers, particularly Trichodesmium [5]. Many mechanisms for iron uptake and utilization in Trichodesmium have been characterized, and the deployment of iron acquisition pathways varies contextually based on chemical and biotic conditions [6-11].

In nature, Trichodesmium forms large colonies that can reach several millimeters in size, with distinct morphologies including "puffs" and "tufts" (e.g., Fig. 1g, h). These colonies harbor complex microbiomes, also referred to as epibionts, with diverse heterotrophic and phototrophic bacterial communities $[12,13]$. The benefits of colony formation have been debated, but there is renewed interest in their utility for particulate iron acquisition [14-17]. This is important because Trichodesmium thrives in regions where iron-rich continental dust is deposited such as the North Atlantic, Red Sea, and near landforms including Australia and the Caribbean islands [18, 19]. Dust addition experiments, both in the laboratory and in shipboard incubations, have demonstrated that Trichodesmium puff colonies can selectively capture [20] and efficiently acquire iron from (oxy/hydro) oxide dust minerals $[14-16,21]$ with the involvement of the epibiont community $[22,23]$. Dust particles can relieve iron stress and improve Trichodesmium's metabolic function [24, 25], but may also act as ballast leading to accelerated sinking of Trichodesmium colonies and enhanced carbon sequestration [26]. The mechanisms allowing Trichodesmium to capture, retain, and dissolve dust particles are therefore of biogeochemical importance.

Here we conducted a combined mineralogical and molecular characterization of individual Trichodesmium colonies all collected from a single plankton net conducted at 17:00 local time on March 11,2018 , in the tropical Atlantic Ocean in the vicinity of the

\footnotetext{
'Department of Marine Chemistry and Geochemistry, Woods Hole Oceanographic Institution, Woods Hole, MA, USA. ${ }^{2}$ Department of Earth, Atmospheric and Planetary Sciences, Massachusetts Institute of Technology, Cambridge, MA, USA. ${ }^{3}$ Marine and Environmental Biology, Department of Biological Sciences, University of Southern California, Los Angeles, CA, USA. ${ }^{4}$ Department of Microbiology, Boston University School of Medicine, Boston, MA, USA. ${ }^{5}$ Department of Biology, Woods Hole Oceanographic Institution, Woods Hole, MA, USA. ${ }^{6}$ Present address: Department of Environmental Systems Science, ETH Zürich, Zürich, Switzerland. ${ }^{7}$ Present address: Department of Earth and Planetary Sciences, Harvard University, Cambridge, MA, USA. ${ }^{凶}$ email: msaito@whoi.edu
}

Received: 22 January 2021 Revised: 10 June 2021 Accepted: 18 June 2021

Published online: 13 July 2021 


\section{a}

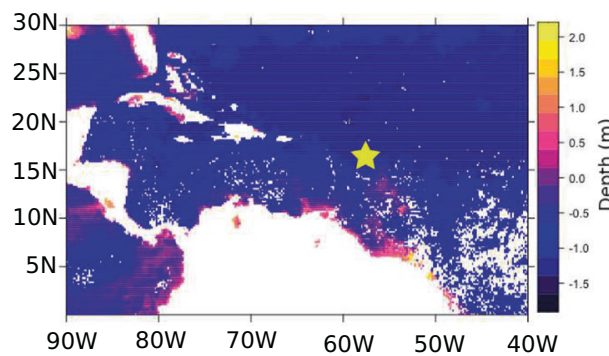

b
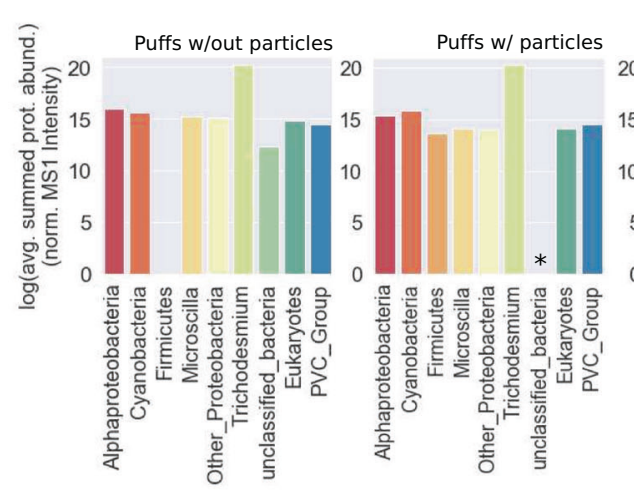

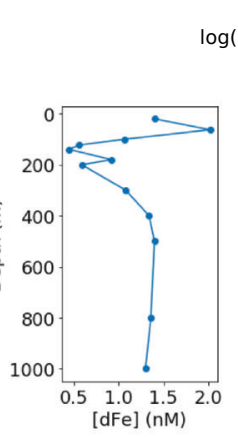

$\log ($ chla)

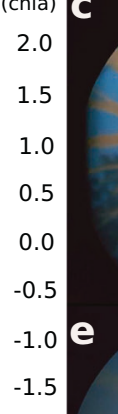

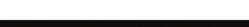
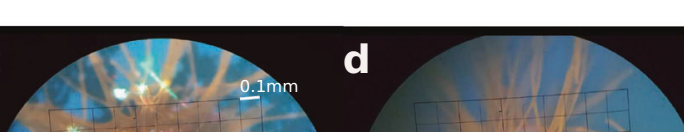

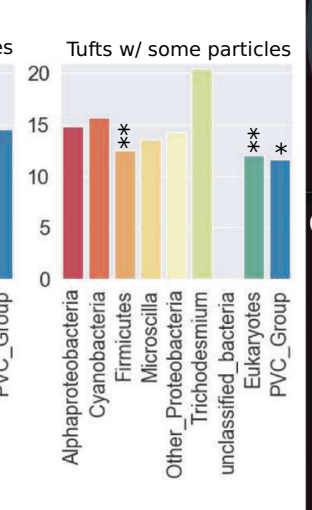

(ives

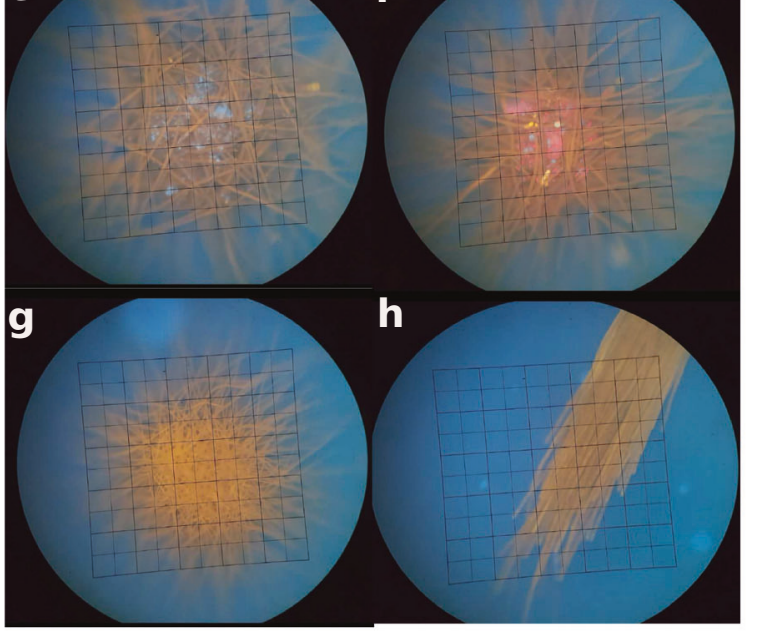

Fig. 1 Overview of sampling location and Trichodesmium population. a Sampling location (yellow star) overlaid on MODIS-Aqua chlorophyll-A data averaged between March 1 and March 31, 2018, with dissolved iron profile at the sampling location. b Biological diversity of the proteins identified in the single-colony metaproteomes, with abundances of all detected proteins summed by major taxonomic groupings and separated by colony morphology. ${ }^{*}$ Indicates significant difference from puffs without particles at $p<0.1,{ }^{* *}$ the same at $p<0.05$, Welch's unequal variance $t$-test. $\mathbf{c}-\mathbf{f}$ Representative images of puff colonies with particles, $\mathbf{g}$ puff without particles, and $\mathbf{h}$ a tuft with some particles. Images were collected in epifluorescent mode using a DAPI long-pass filter set, without dyes. The scale bar in (c) applies to all images.

Orinoco and Amazon river plumes $\left(-57.5^{\circ} \mathrm{W} 16.5^{\circ} \mathrm{N}\right.$, Fig. $\left.1 \mathrm{a}\right)$. Microscopic examination revealed that some, but not all, of the colonies were laden with particulate matter, later confirmed by synchrotron-based element mapping and mineralogical analysis to be iron-oxide and iron-silicate minerals. Subsequent comparative proteomic analysis of individual colonies via a new lowbiomass approach revealed key molecular changes including the deployment of proteins involved in iron uptake and storage, redox regulation, heavy metal detoxification, and chemotaxis machinery which may be involved in particle entrainment. These findings indicate there is a distinct in situ molecular response to particulate iron which likely underlies Trichodesmium's competitiveness and biogeochemical function in high-dust surface ocean ecosystems.

\section{RESULTS AND DISCUSSION}

\section{Oceanographic context of the sampling location}

All Trichodesmium colonies used in this study were collected from the same phytoplankton net which sampled a surface-ocean Southern Caribbean Sea community (Fig. 1a). At the sampling station the phosphate concentration was low $(0.13 \mu \mathrm{M}$ at $100 \mathrm{~m})$ as is typical in an oligotrophic environment, while the surface dissolved iron concentration was relatively high $(2.02 \mathrm{nM}$ at 100 $\mathrm{m})$, consistent with coastal or atmospheric inputs being mobilized in this region (Fig. 1a). By far the most abundant Trichodesmium species at this location was an uncharacterized Trichodesmium thiebautii species, as determined by Trichodesmium-specific metagenome-assembled-genome recruiting (see Table S1).

Thirty individual colonies of mixed morphology were separated by hand-picking, immediately examined, and photographed by fluorescent microscopy (385 excitation, $>420 \mathrm{~nm}$ emission), then frozen individually for particle characterization and metaproteomic analysis (Fig. S1). All colonies used in this study presented as healthy with reddish-orange pigmentation and well-defined shape. When the particles were present they auto-fluoresced in the visual light range, appearing as yellow, red, or blue dots. In general, the particles were concentrated in the center of puff-type colonies, though they were also present in tufts but in smaller numbers. Strikingly, colonies either had many such particles or none at all. Based on prior experimental evidence demonstrating that Trichodesmium colonies can capture mineral particles and access iron from them [14-16, 21], we hypothesized that these particles were terrestrially derived minerals (Fig. 1c-h). Therefore, we embarked to understand the morphological heterogeneity by characterizing the particles and the colony's molecular response to them.

\section{Mineralogical characterization of the colony-associated particles}

To find out whether these natural colonies of Trichodesmium had captured iron-rich mineral particles, we performed synchrotron-based micro-X-ray fluorescence ( $\mu$-XRF) element mapping of representative colonies with the observed particle associations. Prior evidence of Trichodesmium-particle associations has been based mainly on experimental "feeding" of dust to cultured or captured colonies [15, 16, 20, 22-25], and it was therefore important to establish these specific Trichodesmium-particle relationships, which developed in nature. We examined one tuft- and two puff-type colonies, all of which had particles associated with them. The element maps 




Fig. $2 \mu$-XRF-based element maps of a Trichodesmium tuft (left) and puff (right) colony (beamsize $3 \times 3 \boldsymbol{\mu m}$ ). White/gray contours, based on the sulfur panel, which is indicative of biomass, have been provided (white = high [S] threshold, gray =lower [S] threshold). The color scale is the same for each image, with the maximum concentration for each element indicated in parentheses; iron is displayed using two scales. Iron oxidation states were determined via $\mu$ XANES for three particles in the puff colony, and these are annotated in yellow. The corresponding XANES spectra are shown in Fig. S4 and tabulated data in Table S2.

were consistent with the hypothesis that there were mineral particles enriched in iron (Fe), copper (Cu), zinc ( $\mathrm{Zn})$, titanium/ barium ( $\mathrm{Ti} / \mathrm{Ba}$, which cannot be distinguished by this method), manganese $(\mathrm{Mn})$ and cobalt $(\mathrm{Co})$, though the concentrations approached the limit of detection for the latter two elements (Fig. 2, Figs. S2 and S3). Iron concentrations were particularly high in the particles. Micro-X-ray absorption near-edge structure ( $\mu$-XANES) spectra for iron were collected on six particles-three each from the two puffs (Fig. 2 and Fig. S4). The particles contained mineral-bound iron with average oxidation states of 2.6, 2.7, two of oxidation state 2.9 , and two of oxidation state 3.0 (Table S2, Fig. S5). While the mineralogy of these particles could not be definitively resolved using $\mu$-XANES, the structure of the absorption edge and post-edge region provided insight into broad mineral groups. Both Fe(III) (oxy/hydro)oxides and mixed-valence iron-bearing minerals consistent with iron silicates were present, suggesting heterogeneous mineral character. While we could not positively identify the silicate mineral phases based on XANES, the spectroscopic similarity of some samples to iron-smectite and the geologic context suggest iron-bearing clays were present (Fig. S5). In this geographic region, iron oxides and clays could be sourced from atmospheric dust deposition, which is common in this region $[27,28]$ and/or from riverine sources such as the Orinoco and/or Amazon rivers $[29,30]$.

These colony-associated mineral particles likely serve as a simultaneous source of nutritional ( $\mathrm{Fe}, \mathrm{Ni}, \mathrm{Co}, \mathrm{Mn})$ and toxic $(\mathrm{Cu})$ metals to the colonies. The elemental composition of the particles is similar to a recent characterization of Trichodesmium-particle associations in the South Atlantic [30]. Release of metals from the particles likely vary over time, with copper, nickel, zinc, and cobalt continually leaching and iron leaching initially, then re-adsorbing back onto particles unless organic chelates assist in solubilization [31].

\section{Proteome composition is altered by particle presence}

To understand the impact of the particles on colony diversity and function, we performed comparative metaproteomic analysis of the individual Trichodesmium colonies and their microbiota. Seven puffs without particles, 14 puffs with particles, and 4 tufts with particles were analyzed by a new single-colony metaproteomic method. This approach allowed for the first time the molecular profiles of heterogeneous Trichodesmium colonies to be examined individually. Compared to bulk population-level metaproteomes from this location, which achieved deeper resolution of lowabundance proteins by integrating biomass from 50 to 100 colonies (4478 proteins identified) [32], proteome coverage for the low-biomass single colonies was lower yet sufficient for characterizing colony function (2078 proteins identified, Fig. S6) [32]. In total, 1591 Trichodesmium and 487 epibiont proteins were identified across the 25 single-colony metaproteomes versus 2944 Trichodesmium and 1534 epibiont proteins across triplicate population-level metaproteomes (Tables S3 and S4). Phylogenetic exclusivity was checked such that peptides used to identify epibiont proteins were not present in the Trichodesmium genome (Table S5 and Fig. S7) [33, 34].

Trichodesmium's epibiont community plays crucial roles in colony health and physiology, and together the single-colony proteomes demonstrated a diverse and functionally active microbiome associated with the colonies (Fig. 1b and Fig. S8). The proteomic analysis generally reflected the more abundant, "core" members of the epibiont community as was expected given their low-biomass proportion relative to Trichodesmium cells. Many commonly identified epibiont groups were present including Alphaproteobacteria, Microscilla, and non-Trichodesmium cyanobacteria $[12,35,36]$. In general, epibiont abundance was unaffected by particle presence, with one exception: Firmicute proteins were more abundant in tufts and puffs with particles, suggesting enhanced, possibly anaerobic, metabolism. 


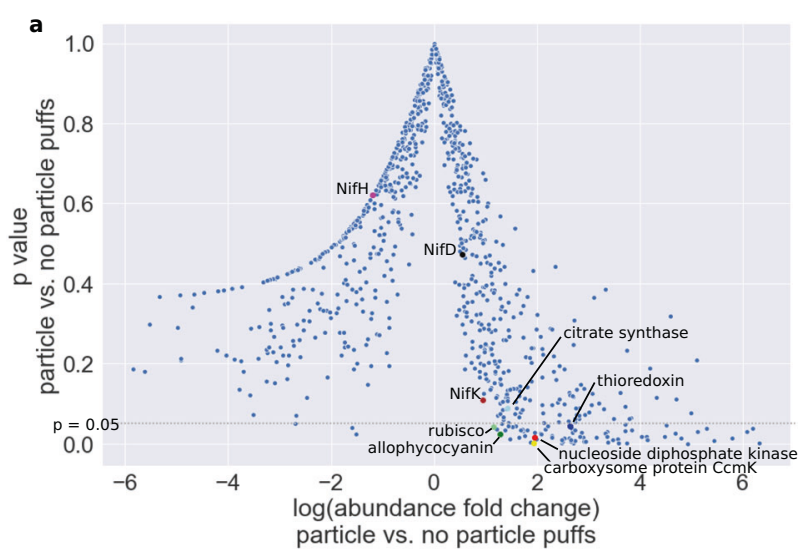

b
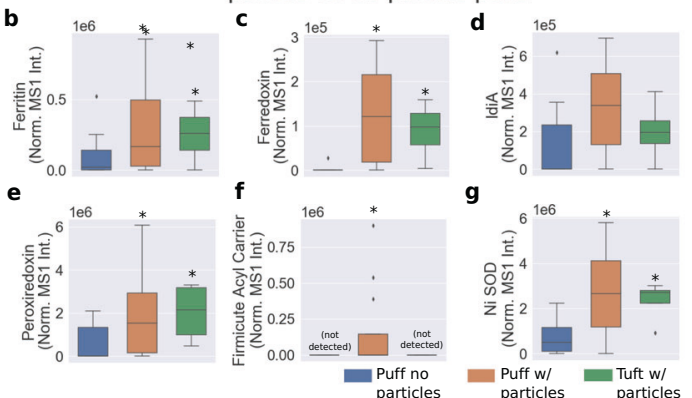

Fig. 3 Proteome responses in colonies with and without particle associations. a $p$ value (Welch's $t$-test) versus protein abundance reported as fold change for puffs with vs. without particles. Only Trichodesmium proteins are displayed. Below the gray dotted line $(p=0.05)$, the differences are statistically significant. Positive fold change indicates the protein was more abundant when particles were present. Proteins of interest are highlighted. b-g Relative abundance of selected proteins for the different colony types, presented as box plots (center line $=$ median, box limits $=$ first and third quartiles, whiskers = data $\min$ and $\max$, diamonds = outliers). * Indicates statistically significant difference compared to the puffs without particles, $p<0.05$.

Greater differences were identified between the puff and tuft morphologies, independent of particle presence and consistent with prior characterizations finding that puffs and tufts harbor distinct epibiont communities [12]. Specifically, eukaryotic proteins were more abundant in puffs compared to tufts. These proteins likely represent copepods due to sequence similarity to the model organism Calanus finmarchicus, and this result is consistent with observed associations between copepods and puffs at this location (Fig. S8B). Notably, proteins from the PVC superphylum, particularly an uncharacterized eukaryote pathogen species related to Chlamydia, were also more abundant in puffs. Eukaryotes are often observed in association with Trichodesmium colonies, but are not always identified due to differences in sampling protocols that could wash them away [12], as well as due to biases in analytical methods, for instance in studies with a focus on bacterial $16 \mathrm{~S}$ or metagenomic analyses. Overall, the differences in the epibiont community were small, suggesting that these do not explain the observed morphological heterogeneity. We therefore turn our attention to describing how the particles impacted the proteome of Trichodesmium specifically.

Mineral presence was associated with significant differences in the Trichodesmium proteome. In total, 131 proteins were differently abundant in puffs with particles versus without particles $(p<0.05$, FDR-controlled Welch's unequal variances $t$-test). Proteome differences were distributed across a variety of biogeochemically relevant proteins, particularly metalloproteins containing iron, nickel, copper, and zinc. Photosynthesis and carbon fixation proteins including Rubisco $(p=0.04)$, citrate synthase $(p=0.08)$, and the accessory pigment allophycocyanin $(p=0.1)$ were more abundant when minerals were present. In fact, most of the differentially abundant proteins were more abundant in the particle-containing colonies suggesting that the colonies with particles were more metabolically active. Particle presence did not affect nitrogenase abundance, consistent with prior laboratory experiments in which Trichodesmium erythraeum filaments were fed concentrated dust [24]. Because nitrogen fixation is a critical process, Trichodesmium may distribute iron to nitrogenase at a steady rate, while altering the activity of other systems in response to the particles. Alternatively, it is possible that nitrogenase activity was being regulated posttranslationally [37] and there were indications of enhanced use and recycling of fixed nitrogen compounds; the nitrogen assimilation proteins glutamine synthetase $(p=0.008)$, spermidine synthase $(p=0.005)$, and a urea transporter $(p=0.02)$ were enriched in colonies with particles (see Fig. S9) [32].

\section{Responses in iron uptake and utilization proteins}

The broadest and strongest proteome response occurred in ironrelated proteins, consistent with Trichodesmium's strong dependence on iron availability. Several iron-containing proteins were significantly more abundant when particles were present, suggesting that the particles acted as a micronutrient source. These included an iron-containing peroxidase $(p=0.03)$, the electron transport protein ferredoxin $\mathrm{fdxH}(p=0.0006)$, and the iron storage/DNA binding protein Dps-ferritin $(p=0.002)$ (Fig. 3). Together, the coordinated response of each of these proteins suggests that the minerals were a nutritional source of iron. For instance, increased abundance of ferredoxin is consistent with increased iron availability, since the non-iron-containing flavodoxin is substituted for ferredoxin during iron stress $[6,38,39]$. Similarly, increased abundance of Dps-ferritin would serve to buffer and store iron acquired from the concentrated particulate metal source. In addition to binding iron, the Dps-ferritin may also serve to protect DNA from photooxidative damage, and this in addition to the peroxidase signal may indicate increased oxidative stress in the colonies with particles [40]. The clear increase in Dpsferritin protein abundance in the presence of mineral particles differs from a prior report, which found no change in bacterioferritin transcript abundance when cultured $T$. erythraeum was fed Saharan desert dust [24]. It is possible that Dps-ferritin and bacterioferritin respond to distinct cellular conditions, for instance Dps-ferritin may have been preferred by these colonies because of its dual function for iron storage and protection against oxidative stress. This difference highlights the potential challenges in comparing laboratory and field studies, as well as the oftensuggested importance of post-transcriptional and posttranslational controls in Trichodesmium [32, 37, 41]. Given the high iron demand of the nitrogenase metalloenzyme, the ability to store iron from rich but episodically available mineral particles could provide an important ecological niche in oceanic environments where iron can be scarce and its solubility is low.

Multiple uptake mechanisms were involved in obtaining iron from the mineral particles. While iron acquisition in Trichodesmium is not well characterized, at least three systems are known to exist in the genome: the FeoB system (Fe(II)), the IdiA system (Fe(III)), and uptake via Fe-siderophores [9, 11]. The single-colony metaproteomes provided evidence for the deployment of the latter two mechanisms in the natural environment; FeoB is rarely identified in field metaproteomes of diazotrophs, possibly due to its low copy number and high efficiency (Fig. 4) [38, 39, 42]. Despite evidence that the particles provided iron to the colonies, the periplasmic iron transport protein IdiA was more abundant during particle associations ( $p=0.16$ ) (Fig. $3 d$ ). IdiA is often used as a biomarker of iron stress because it is responsive to/more abundant in low iron conditions [32, 38, 39]. Increased IdiA abundance was confusing because it suggested that the particle- 


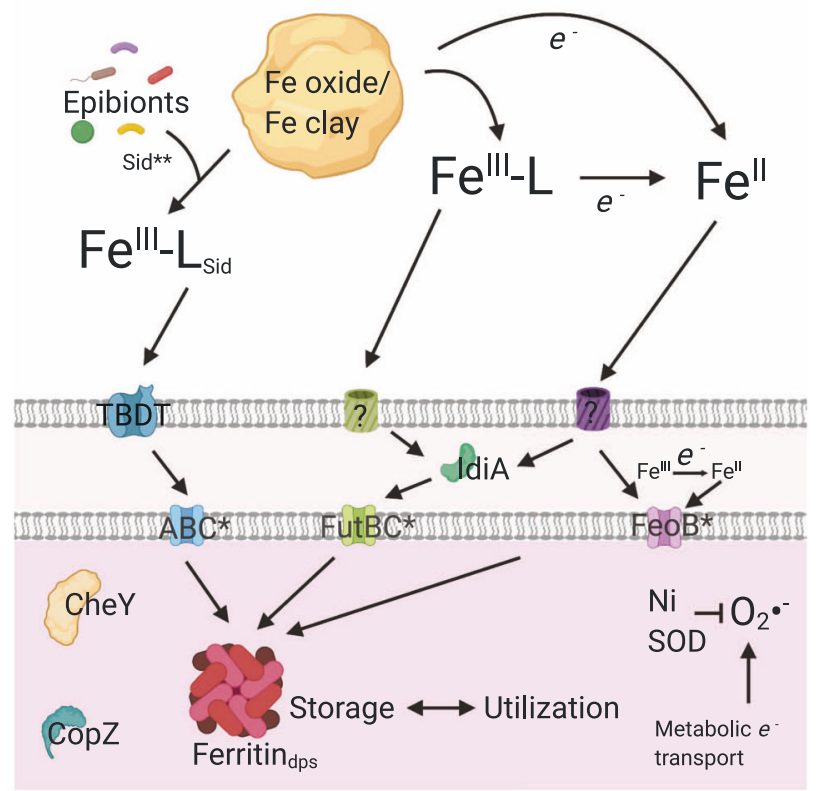

Fig. 4 Current model of iron uptake and use mechanisms involved in utilization of particle-derived iron, based on mineralogical and proteomic observations in this and prior studies. Fe (III)- $\mathrm{L}$ and $\mathrm{Fe}$ (II) are thought to enter the periplasm through unknown passive porins/receptors (green and purple proteins labeled "?") [9]. Iron acquisition proteins with annotated names are identified, otherwise the following general functional names are used: TBDT unspecified TonB dependent transporter, $A B C$ unspecified $A B C$ transporter, Ni SOD nickel superoxide dismutase, $C$ heY chemotaxis response regulator, CopZ copper chaperone. IdiA preferentially binds iron in the Fe(III) state but may also bind $\mathrm{Fe}(\mathrm{II})$ [11]. e- indicates any general reductant, which could include extracellular superoxide. * Indicates iron acquisition proteins that were not identified in this study. ${ }^{* *}$ Evidence from this study suggests that the Firmicute epibionts were producing siderophores.

associated colonies were more iron limited, a conclusion that is not supported by the increase in iron storage and utilization proteins described above. One interpretation is that IdiA serves a function in acquiring iron from the mineral particles. Due to its binding preference for $\mathrm{Fe}(\mathrm{III})$ [11] this could include uptake from a ligand-bound $\mathrm{Fe}(\mathrm{III})$ state that may aid in particle dissolution $[11,43,44]$. In this way, IdiA may have a different functional response to particulate versus dissolved iron. There was also evidence that iron-binding siderophore systems synthesized by the bacterial epibionts were involved: a Firmicute acyl carrier protein putatively involved in siderophore production was enriched in puffs with particles (Fig. 3f, $p=0.04$ ). Trichodesmium does not seem to produce siderophores, but it can acquire siderophore-bound iron produced via mutualistic interactions with epibionts, especially when provided with concentrated dust $[9,22,23,43]$. Corroborating this, a Trichodesmium TonBdependent transporter (TBDT) for ferrienterochelin/colicins was identified only in puffs with particles [45].

A crucial role for redox regulation when particles were present The enzyme nickel superoxide dismutase (Ni SOD) was significantly more abundant in the mineral-associated colonies (Fig. $3 \mathrm{~g}$, $p=0.004)$, reflecting the need to regulate the reactive oxygen species (ROS) superoxide in the presence of particles. There are multiple reasons for elevated superoxide production in particleassociated colonies. First, metabolic electron transport is associated with incidental superoxide production, and electron transport seems to have been enhanced in the presence of particles as indicated by the enrichment of photosynthesis proteins. Furthermore, Trichodesmium has among the highest Mehler reaction activity of any photosynthetic organism, and this may contribute to internal superoxide production [46]. Indeed, this evidence of an abundant ROS detoxification enzyme is consistent with intracellular superoxide production and indicates that the traditional Mehler reaction is important in field populations. Additional redox-regulating proteins including peroxiredoxin, thioredoxin, and Dps-ferritin were more abundant when particles were present (see Fig. 3e, $p=0.03$ and 0.04 , respectively, for puffs with and without particles), consistent with elevated ROS in particle-containing colonies. Increased superoxide dismutase protein may also reflect enhanced nickel availability when particles were present. Nickel is an essential nutrient for Trichodesmium, and can limit nitrogen fixation due to Trichodesmium's significant need for superoxide dismutase to protect the nitrogenase enzyme [47].

An additional explanation for increased superoxide dismutase protein abundance is that it indirectly reflected iron uptake processes and/or extracellular iron reduction. Reduced iron transported into the cell could react with intracellular oxygen, leading to increased superoxide formation; [48] this could trigger superoxide dismutase production to maintain healthy intracellular superoxide levels [49]. Puffs in particular are known to closely regulate superoxide levels with a possible link to cell signaling and growth [50]. Extracellular superoxide production may also play a role in iron uptake, as has been suggested previously [9]. This extracellular superoxide production may indirectly contribute to intracellular superoxide dismutase signals via $\mathrm{Fe}(\mathrm{II})$ uptake as described above, but because superoxide does not cross cell membranes, this does not directly explain the observed signal in intracellular superoxide dismutase [51]. Besides extracellular superoxide, other mechanisms of reductive iron uptake have been suggested including reactive metabolites and extracellular proteins on the cell surface [9]. Recent observations have tied hydrogen physiology to mineral iron uptake, however, the underlying biochemical system remains unknown [21]. Systems such as the alternative respiratory terminal oxidase (ARTO) have been invoked [52], but this protein was not detected, implying it was not a major constituent of the proteome, though as in the above case of FeoB it is possible that ARTO was present in low concentrations and was highly active. The putative role of ARTO is furthermore unclear because a recent study observed that ARTO transcript abundance was lower in the presence of dust, and not enhanced as might be expected if ARTO is involved in iron uptake [24].

Involvement of chemotaxis machinery in particle entrainment A prior study captured impressive visual observations of Trichodesmium responses to dust, where experimentally provided particles were captured and transported to the colony center [15]. This behavior was seen primarily in puff-type colonies isolated from the field, indicating that these natural populations may react differently to dust than laboratory Trichodesmium strains. Consistent with prior studies $[15,20]$, the mineral particles were concentrated in the center of puff-type colonies and this may enhance the efficiency of extracellular iron reduction pathways by reducing diffusive loss [53]. Moreover, the proteomic characterization from this study provides molecular insight into this behavior. Here we observed that movement proteins including a SwmA-like RTX protein $(p=0.1)$ [54] and chemotaxis regulator CheY $(p=0.3)$ were enriched when particles were present (Fig. S9E-H), indicating that they were involved in the particle capturing behavior observed by Rubin et al. [15]. In previously published bulk metaproteomes of field Trichodesmium populations, there was an observed relationship between the $\mathrm{CheY}$ protein and the iron transport protein IdiA, suggesting a link between chemotaxis and particulate iron acquisition [32]. While there is more to be learned about how this system operates, it appears that the chemotaxis and iron regulatory systems are connected and responding directly to particulate iron. 
Evidence for a specific regulatory response to particulate iron in Trichodesmium

Taken together, the in situ biochemical observation points to a model in which Trichodesmium colonies differentiate between dissolved versus particulate iron. First, consistent with the mineralogical profile of the particles, the colonies engaged multiple iron uptake mechanisms and also prioritized balancing cellular redox status during enhanced productivity and iron uptake (Fig. 4). Once inside the cell, mineral-derived iron was preferentially stored via Dps-ferritin. This finding adds complexity to the canonical regulatory model that IdiA and ferritin exist on a continuum with IdiA abundant during iron limitation and ferritin present only when iron is replete. It suggests that Trichodesmium alters uptake and utilization mechanisms in response to the iron's coordination environment, specifically to the particulate vs. dissolved phase. Whether Trichodesmium makes the distinction directly via a specific mineral sensing mechanism, or indirectly due to increased intracellular metal concentration, is not yet known. Trichodesmium has an unusually large number of uncharacterized two-component sensory systems relative to other phytoplankton, and it is possible that one or more of these systems is involved, which would further imply the involvement of metal-binding ligands [55]. Either way, it is clear that multiple metabolic and homeostasis systems were involved in this coordinated response to the presence of particulate iron, and it does seem likely that iron-specific regulatory processes are involved since in laboratory studies Trichodesmium is able to distinguish between ironcontaining and non-iron-containing particulate matter [20]. A final intriguing aspect of particle-associated Trichodesmium colonies was the deployment of Cu-related proteins. Trichodesmium is known to be extraordinarily sensitive to Cu toxicity [56], and close proximity to mineral particles was associated with enrichment of the copper chaperone/homeostasis protein CopZ $(p=0.06$ and Fig. S9D) [57], suggesting the need for metal detoxification when minerals were present.

\section{Conclusion}

This study provides direct evidence that Trichodesmium colonies capture and process oxide and silicate minerals in situ, and that colonies alter key aspects of their biochemistry in response. These findings highlight heterogeneity in the morphological and molecular profiles of Trichodesmium colonies in nature, revealed by a new approach in which colony proteomes are analyzed individually. The underlying mechanisms for this heterogeneity are multiple and likely intersect. One important aspect is stochastics of colony-particle encounters due to patchy dust availability. In addition, the sampled population might represent a mixture of Trichodesmium colonies advected from geographical locations or water column environments/depths with different particle loadings. Other explanations could include sub-species differences among the colonies, unresolved changes in the epibiont community, and past physiological history of the colony such as age or past iron status. Clearly much is still to be discovered about the reasons for and implications of physiological heterogeneity in natural marine microbial populations.

Trichodesmium thrives in high-dust environments and this study provides clear evidence for the biochemical basis behind this specialized niche. The results have ecological and geochemical implications beyond Trichodesmium biology. Specifically, active capture and degradation of mineral particles may increase iron availability in the oligotrophic surface ocean. In this way, abundant Trichodesmium colonies may have an important role in the leaching of particulate trace metals and the supply of bioavailable iron to the euphotic zone, not least because Trichodesmium colonies tend to be neutrally or positively buoyant $[58,59]$ and can therefore retain mineral matter at the surface. Mineral capture and degradation may therefore have significant implications for global iron and carbon cycling [60]. Furthermore, the coupled mineralogical and biochemical characterization of single colonies present evidence for specific responses to mineral particles that could be leveraged to improve future biogeochemical and marine ecosystem models. Particulate iron utilization by Trichodesmium appears to be a critical niche, and is likely a significant factor determining this organism's ecological success and fixed nitrogen contributions to the global ocean.

\section{MATERIALS AND METHODS}

\section{Sampling and microscopy}

All of the colonies used in this study were sampled from a single plankton net conducted at $-57.5^{\circ} \mathrm{W} 16.5^{\circ} \mathrm{N}$ at 17:00 local time on March 11, 2018, on the AT39-05/Tricolim expedition (R.V. Atlantis, Chief Scientist D. Hutchins, https://www.bco-dmo.org/deployment/765978). A 130- $\mu$ m net was released to approximately $20 \mathrm{~m}$ depth, then pulled back to the surface and the process repeated five times. Colonies were handpicked by gentle pipetting, rinsed twice in $0.2-\mu \mathrm{m}$-filtered trace metal clean seawater, and decanted into $0.2-\mu \mathrm{m}$ sterile filtered trace metal seawater until imaging. All at-sea colony picking and handling was conducted in a Class 100 trace metal clean environment. Colonies were imaged with a Zeiss epifluorescent microscope using transmitted light and/or a long-pass fluorescent filter set. At the time of imaging, they were labeled as "particle containing" or not and classified as puffs or tufts. They were then decanted individually onto trace metal clean $0.2-\mu \mathrm{m}$ Supor filters and flash frozen in liquid nitrogen, then stored at $-80^{\circ} \mathrm{C}$ until analysis at the home laboratory. Images were captured with a Samsung Galaxy Note 4 using a SnapZoom universal digiscoping adapter. MODIS-Aqua data for Fig. 1a was obtained from the NASA Goddard Space Flight Center, Ocean Ecology Laboratory, Ocean Biology Processing Group; (2014): Sea-viewing Wide Field-of-view Sensor (SeaWiFS) Ocean Color Data, NASA OB.DAAC Accessed on 2020-04-08.

\section{Nutrient and trace metal analyses}

Seawater was sampled using a trace metal clean rosette consisting of Niskin$\mathrm{X}$ bottles. Niskins were pressurized with nitrogen gas in a shipboard Class 100 clean room and seawater was filtered through $0.2-\mu \mathrm{m}$ Supor membranes to remove particles. Aliquots for macronutrient (phosphate) analysis were frozen immediately at sea and were thawed just prior to analysis. Phosphate was quantified using a Technicon Autoanalyzer II by Joe Jennings at Oregon State University. Aliquots for dissolved metal analysis were acidified with concentrated trace metal clean $\mathrm{HCl}$ (Seastar) to $\mathrm{pH} 1.8$ and allowed to equilibrate for $\sim 1$ month prior to analysis. Dissolved iron was concentrated using a seaFAST automated pre-concentration system and quantified on an ICAP Q inductively coupled plasma mass spectrometer (ICP-MS).

\section{Sample handling and preparation for single-colony proteomics}

Upon return to the lab, the colonies were carefully cut out of the filter to reduce the volume of liquid needed for protein extraction. The filter sections were submerged in PBS buffer with $1 \%$ sodium dodecyl sulfate (SDS), $1 \mathrm{mM}$ magnesium chloride, $2 \mathrm{M}$ urea, heated at $95^{\circ} \mathrm{C}$ for $10 \mathrm{~min}$, then shaken at room temperature for $1 \mathrm{~h}$. The extracts were then treated with benzonase nuclease for $30 \mathrm{~min}$ at $37{ }^{\circ} \mathrm{C}$. Proteins in the resulting supernatant were quantified by the BCA assay. Total protein content varied from $<1-10 \mu \mathrm{g}$ among the colonies, and scaled with colony size. The proteins were digested with a modified polyacrylamide tube gel protocol following Saito et al. 2014 in part to purify the protein biomass from any particulate matter Instead of the typical $200 \mu \mathrm{L}$ final gel volume only $50 \mu \mathrm{L}$ final volume was used to minimize protein loss [61, 62]. In addition, the protein precipitation/purification step was eliminated because this is another source of total protein loss. Instead, the samples were treated with benzonase nuclease during the initial extraction phase to solubilize any DNA/RNA components, allowing the purification step to be skipped. Briefly, the proteins were embedded in an acrylamide gel, washed with a 50:50 acetonitrile: $25 \mathrm{mM}$ ammonium bicarbonate buffer, dehydrated by acetonitrile treatment, then treated for $1 \mathrm{~h}$ at $56^{\circ} \mathrm{C}$ with $10 \mathrm{mM}$ dithiothreitol in $25 \mathrm{mM}$ ammonium bicarbonate followed by $1 \mathrm{~h}$ at room temperature with $55 \mathrm{mM}$ iodacetamide. Gels were dehydrated again and rehydrated in trypsin (Promega Gold) at a ratio of $1 \mu \mathrm{g}$ trypsin: $20 \mu \mathrm{g}$ total protein in $25 \mathrm{mM}$ ammonium bicarbonate. Proteins were digested overnight at $37{ }^{\circ} \mathrm{C}$ with shaking. The peptides were then extracted from the gels in $20 \mu \mathrm{L}$ peptide extraction buffer (50\% acetonitrile, $5 \%$ formic acid in water). The resulting peptide mixtures were concentrated to $0.2 \mu \mathrm{g}$ 
total protein/ $\mu \mathrm{L}$ final concentration. While the tube gel method was used for samples presented here, magnetic bead and soluble protein digestion methods were also tested. Total protein recovery was lower with these methodologies, perhaps because these methods do not use SDS, which in our hands is a good lysing agent for Trichodesmium.

\section{LC-MS/MS analysis}

Metaproteome analyses were conducted by tandem mass spectrometry on a Thermo Orbitrap Fusion using $0.5 \mu \mathrm{g}$ total protein injections and a onedimensional $120 \mathrm{~min}$ non-linear gradient on a $15 \mathrm{~cm} \mathrm{C18} \mathrm{column}(100 \mu \mathrm{m} \times$ $150 \mathrm{~mm}, 3 \mu \mathrm{m}$ particle size, $120 \AA$ pore size, C18 Reprosil-Gold, Dr. Maisch $\mathrm{GmbH}$ packed in a New Objective PicoFrit column). LC lines were shortened when possible to reduce the possibility of sample loss to the tubes. Blanks were run between each sample to avoid carryover effects. For each run 0.5 $\mu \mathrm{g}$ of protein was injected directly the column using a Thermo Dionex Ultimate3000 RSLCnano system (Waltham, MA); if less than $0.5 \mu \mathrm{g}$ of protein was available, the entire sample was injected. The samples were analyzed on a Thermo Orbitrap Fusion mass spectrometer with a Thermo Flex ion source (Waltham, MA). MS1 scans were monitored between 380 and $1580 \mathrm{~m} / \mathrm{z}$, with a $1.6 \mathrm{~m} / \mathrm{z} \mathrm{MS} 2$ isolation window (CID mode), $50 \mathrm{~ms}$ maximum injection time and $5 \mathrm{~s}$ dynamic exclusion time. The resulting spectra have been deposited to the ProteomeXchange Consortium via the PRIDE partner repository with the dataset identifier PXD016330 and 10.6019/PXD016330 [63].

\section{Bioinformatics analyses}

The spectra were searched using the SEQUEST algorithm with a customdesigned Trichodesmium sequence database composed from a publicly available Trichodesmium metagenome, trimmed based on a prior bulk metaproteomic analysis, and location-specific metagenome-assembled genomes (MAGs) of Trichodesmium and the epibiont community (Fig. S10). To trim the metagenome sequence database, triplicate Tricho-enriched bulk metaproteomes from the same location (aka "population biomass" samples), each integrating $\sim 50$ to 100 colonies handpicked from the same plankton net, were analyzed using a publicly available Trichodesmium consortia metagenome collected at Station BATS (IMG ID 2156126005). All proteins identified at the $1 \%$ protein and peptide FDR level (Scaffold software, Proteome Software, Inc) were then carried forward into the custom-designed sequence database. Next, to improve coverage of the specific sampled population, hand-refined metagenome-assembled genomes from Trichodesmium populations throughout the AT39-05 transect were also added to the database: these included four $T$. thiebautii species (one H94 species and three uncharacterized T. thiebautiis) and 17 MAGs from the epibiont community.

The single-colony metaproteomes were searched using the SEQUEST search engine with parent mass tolerance $\pm 10 \mathrm{ppm}$ and fragment mass tolerance 0.8 Dalton, allowing cysteine modification of +57.022 Daltons and methionine modification of +16 Daltons. The results were statistically validated at the $1 \%$ FDR level using the Scaffold program (Proteome Software, Inc).

The custom-designed sequence database was crucial in improving coverage of the proteome at the single-colony level. When the data were searched with the entire Trichodesmium consortial metagenome (IMG ID 2156126005,240447 protein-encoding genes), only 800 proteins were identified at the $1 \%$ protein and peptide FDR level due to mis-match of the sequence database size to the proteome diversity of the sample $[64,65]$. Trimming the search space to focus on proteins identified in the bulk metaproteome analysis (reducing the sequence database to 4478 proteins) nearly doubled the number of proteins identified, to 1495 proteins. Including the location-specific MAGs enhanced the coverage further, with 2078 proteins being finally identified in the final search using the final custom database.

Peptides used to identify Trichodesmium proteins were determined to be phylogenetically exclusive to the genus using the open source Metatryp software package last accessed on May 23, 2020 [33, 34]. Statistical tests (Welch's $t$ tests) were performed using the Scipy stats python library and the results are reported in Table S1. $P$ values were FDR controlled by the Benjamini-Hochberg procedure; at $a=0.05$ and $a=0.1$, the calculated FDR was $0 \%$; the FDR rose to $0.56 \%$ by $a=0.25$.

\section{Micro-X-ray fluorescence and Micro-X-ray absorption spectroscopy}

$\mu$-XRF and micro-X-ray absorption spectroscopy ( $\mu$-XAS) were conducted at the Stanford Synchrotron Radiation Lightsource on beamline 2-3 with a 3 $\mu \mathrm{m}$ raster and a $50 \mathrm{~ms}$ dwell time on each pixel. $\mu$-XRF data were analyzed using MicroAnalysis Toolkit [66]. Elemental concentrations were determined using standard foils containing each element of interest. The relative proportions of $\mathrm{Fe}$ (II) and $\mathrm{Fe}$ (III) were determined by fitting the edge position of the background subtracted, normalized XANES spectra. Fe XANES spectra were fit using the SIXPACK Software package [67], and redox state was estimated by conducting a linear combination fitting of the absorption edge $(7115-7140 \mathrm{eV})$ using the model compounds siderite $\left(\mathrm{FeCO}_{3}\right)$ and two-line ferrihydrite as end-member representatives of $\mathrm{Fe}$ (II) and $\mathrm{Fe}$ (III), respectively. Further, these values were confirmed through deconvolution of the edge shape using Gaussian peaks at two fixed energies corresponding to primary $\mathrm{Fe}$ (II) $(7122 \mathrm{eV})$ and $\mathrm{Fe}$ (III) $(7126 \mathrm{eV})$ contributions (PeakFit software, SeaSolve Inc.) [68]. Linear combinations of the empirical model spectra were optimized where the only adjustable parameters were the fractions of each model compound contributing to the fit. The goodness of fit was established by minimization of the R-factor [69, 70].

Although mineral identity cannot be conclusively determined with XANES, visual comparison of the edge features are indicative of broad Fe-bearing mineral groups including many common oxide and silicate minerals. Thus, to get a general sense of mineral groups, we have included several of the top spectral library query hits (Fig. S4) for the six particles we looked at in this study. These include two-line ferrihydrite and goethite (as Fe oxyhydroxide phases), ferrosmectite (as Fe-bearing secondary clays), and biotite (as a primary silicate). We also included siderite (as an Fe(II)-bearing carbonate) in Fig. S4 for comparison to a pure $\mathrm{Fe}(\mathrm{II})$ phase.

\section{Image contour analysis for element concentration maps}

Image contours were generated for the sulfur element concentration maps in Fig. 2 using the Scikit-image python library [71]. First, using the contrast histograms for the sulfur images, algorithmically defined thresholds were applied. For the tuft image in Fig. 2, two thresholds were used to capture the high and low-biomass regions. The resulting binary images were then morphologically dilated to remove noise and connect gaps between objects. A list of contours for the binary image was generated using the marching squares/cubes algorithm [72]. The longest contours were overlaid on the element maps from which they were generated.

\section{DATA AVAILABILITY}

All data are provided in the main text or as supplementary materials. In addition, the mass spectrometry proteomics data have been deposited to the ProteomeXchange Consortium via the PRIDE partner repository with the dataset identifier PXD016330 and 10.6019/PXD016330. The processed proteomics data can also be accessed at BCO-DMO (https://doi.org/10.26008/1912/bco-dmo.786694.1).

\section{CODE AVAILABILITY}

Data analyses and plotting were conducted in Python 3.0 (https://www.python.org/) using the pandas (https://pandas.pydata.org/), matplotlib (https://matplotlib.org/), seaborn (https://seaborn.pydata.org/), scipy stats (https://scipy.org/), and scikit-image (https://scikit-image.org/) libraries. Fully reproducible example code, including statistical analyses, can be found at https://github.com/naheld/ Tricho_Singlecolony_MetaP.

\section{REFERENCES}

1. Falkowski PG. Evolution of the nitrogen cycle and its influence on the biological sequestration of $\mathrm{CO}_{2}$ in the ocean. Nature. 1997;387:272-5.

2. Zehr JP, Capone DG. Changing perspectives in marine nitrogen fixation. Science. 2020;9514:729.

3. Capone DG, Zehr JP, Paerl HW, Bergman B, Carpenter EJ. Trichodesmium, a globally significant marine cyanobacterium. Science. 1997;276:1221-9.

4. Bergman B, Sandh G, Lin S, Larsson J, Carpenter EJ. Trichodesmium-a widespread marine cyanobacterium with unusual nitrogen fixation properties. FEMS Microbiol Rev. 2013;37:286-302.

5. Kustka A, Sañudo-Wilhelmy S, Carpenter EJ, Capone DG, Raven JA. A revised estimate of the iron use efficiency of nitrogen fixation, with special reference to the marine cyanobacterium Trichodesmium spp. (Cyanophyta). J Phycol. 2003;39:12-25.

6. Chappell PD, Moffett JW, Hynes AM, Webb EA. Molecular evidence of iron limitation and availability in the global diazotroph Trichodesmium. ISME J. 2012;6:1728-39. 
7. Paerl HW, Prufert-Bebout ILE, Guo C, Carolina N. Iron-stimulated $\mathrm{N}_{2}$ fixation and growth in natural and cultured populations of the planktonic marine cyanobacteria Trichodesmium spp. Appl Environ Microbiol. 1994;60:1044-7.

8. Sohm JA, Webb EA, Capone DG. Emerging patterns of marine nitrogen fixation. Nat Rev Microbiol. 2011;9:499-508.

9. Roe KL, Barbeau KA. Uptake mechanisms for inorganic iron and ferric citrate in Trichodesmium erythraeum IMS101. Metallomics. 2014;6:2042-51.

10. Boatman TG, Davey PA, Lawson T, Geider RJ. The physiological cost of diazotrophy for Trichodesmium erythraeum IMS101. PLoS ONE. 2018;13:1-24.

11. Polyviou D, Machelett MM, Hitchcock A, Baylay AJ, MacMillan F, Moore CM, et al. Structural and functional characterization of IdiA/FutA (Tery_3377), an ironbinding protein from the ocean diazotroph Trichodesmium erythraeum. J Biol Chem. 2018;293:18099-109.

12. Hmelo LR, Van Mooy BAS, Mincer TJ. Characterization of bacterial epibionts on the cyanobacterium Trichodesmium. Aquat Microb Ecol. 2012;67:1-14.

13. Rouco M, Haley ST, Dyhrman ST. Microbial diversity within the Trichodesmium holobiont. Environ Microbiol. 2016;18:5151-60.

14. Rueter JG, Hutchins DA, Smith RW, Unsworth NL. Iron nutrition of Trichodesmium. In: Carpenter EJ, Capone DG, Rueter JG, editors. Marine pelagic cyanobacteria: Trichodesmium and other diazotrophs. Dordrecht, The Netherlands: Kluwer Academic Publishers; 1992. p. 289-30.

15. Rubin M, Berman-Frank I, Shaked Y. Dust-and mineral-iron utilization by the marine dinitrogen-fixer Trichodesmium. Nat Geosci. 2011;4:529-34.

16. Basu S, Shaked Y. Mineral iron utilization by natural and cultured Trichodesmium and associated bacteria. Limnol Oceanogr. 2018;63:2307-20.

17. Tzubari Y, Magnezi L, Be'Er A, Berman-Frank I. Iron and phosphorus deprivation induce sociality in the marine bloom-forming cyanobacterium Trichodesmium. ISME J. 2018;12:1682-93.

18. Sinnott-Armstrong NA, Greene CS, Cancare F, Moore JH. Large-scale distribution of Atlantic nitrogen fixation controlled by iron availability. Nat Geosci. 2009:2:867-71.

19. Monteiro FM, Dutkiewicz S, Follows MJ. Biogeographical controls on the marine nitrogen fixers. Global Biogeochem Cycles. 2011;25:1-8.

20. Kessler N, Armoza-Zvuloni R, Wang S, Basu S, Weber PK, Stuart RK, et al. Selective collection of iron-rich dust particles by natural Trichodesmium colonies. ISME J. 2020;14:91-103.

21. Eichner M, Basu S, Gledhill M, De Beer D, Shaked Y. Hydrogen dynamics in Trichodesmium colonies and their potential role in mineral iron acquisition. Front Microbiol. 2019;10:1-12.

22. Kessler N, Kraemer SM, Shaked Y, Schenkeveld WDC. Investigation of siderophore-promoted and reductive dissolution of dust in marine microenvironments such as Trichodesmium colonies. Front Mar Sci. 2020;7:1-16.

23. Basu S, Gledhill M, de Beer D, Prabhu Matondkar SG, Shaked Y. Colonies of marine cyanobacteria Trichodesmium interact with associated bacteria to acquire iron from dust. Commun Biol. 2019;2:1-8.

24. Polyviou D, Baylay AJ, Hitchcock A, Robidart J, Moore CM, Bibby TS. Desert dust as a source of iron to the globally important diazotroph Trichodesmium. Front Microbiol. 2018;8:1-12

25. Rj L, Mm M, Ridame C, Croot P, LaRoche J. Diazotrophic bacteria respond to Saharan dust additions. Mar Ecol Prog Ser. 2012;470:1-14.

26. Pabortsava K, Lampitt RS, Benson J, Crowe C, McLachlan R, Le Moigne FAC, et al. Carbon sequestration in the deep Atlantic enhanced by Saharan dust. Nat Geosci. 2017:10:189-94.

27. Kaufman YJ. Dust transport and deposition observed from the Terra-Moderate Resolution Imaging Spectroradiometer (MODIS) spacecraft over the Atlantic Ocean. J Geophys Res D Atmos. 2005;110:1-16.

28. Caquineau S, Gaudichet A, Gomes L, Legrand M. Mineralogy of Saharan dust transported over northwestern tropical Atlantic Ocean in relation to source regions. J Geophys Res Atmos 2002;107:AAC 4-1-AAC 4-12.

29. Waite TD, Szymczak R. Particulate iron formation dynamics in surface waters of the eastern Caribbean. J Geophys Res. 1993;98:2371-83.

30. Bif MB, Yunes JS. Distribution of the marine cyanobacteria Trichodesmium and their association with iron-rich particles in the South Atlantic Ocean. Aquat Microb Ecol. 2017;78:107-19.

31. Mackey KRM, Chien C, Te, Post AF, Saito MA, Paytan A. Rapid and gradual modes of aerosol trace metal dissolution in seawater. Front Microbiol. 2015;6:1-11.

32. Held NA, Webb EA, Mcllvin MM, Hutchins DA, Cohen NR, Moran DM, et al. Cooccurrence of $\mathrm{Fe}$ and $\mathrm{P}$ stress in natural populations of the marine diazotroph Trichodesmium. Biogeosciences. 2020;17:2537-51.

33. Saito MA, Dorsk A, Post AF, Mcllvin MR, Rappe MS, DiTullio GR, et al. Needles in the blue sea: Sub-species specificity in targeted protein biomarker analyses within the vast oceanic microbial metaproteome. Proteomics, n/a-n/a. 2015 https://doi.org/10.1002/pmic.201400630.

34. Saunders JK, Gaylord DA, Held NA, Symmonds N, Dupont CL, Shepherd A, et al. METATRYP $\vee$ 2.0: Metaproteomic least common ancestor analysis for taxonomic inference using specialized sequence assemblies_-standalone software and web servers for marine microorganisms and coronaviruses. J Proteome Res. 2020. https://doi.org/10.1021/acs.jproteome.0c00385.

35. Frischkorn KR, Rouco M, Van Mooy BAS, Dyhrman ST. Epibionts dominate metabolic functional potential of Trichodesmium colonies from the oligotrophic ocean. 2017:2090-101. https://doi.org/10.1038/ismej.2017.74.

36. Lee MD, Webb EA, Walworth NG, Fu F, Held NA, Saito MA, et al. The Trichodesmium consortium: conserved heterotrophic co-occurrence and genomic signatures of potential interactions. ISME J. 2017:1-12. https://doi.org/10.1038/ ismej.2017.49.

37. Zehr JP, Wyman M, Miller V, Capone DG, Duguay L. Modification of the Fe protein of nitrogenase in natural populations of Trichodesmium thiebautii. Appl Environ Microbiol. 1993;59:669-76.

38. Chappell PD, Webb EA. A molecular assessment of the iron stress response in the two phylogenetic clades of Trichodesmium. Environ Microbiol. 2010;12:13-27.

39. Snow JT, Polyviou D, Skipp P, Chrismas NA, Hitchcock A, Geider R, et al. Quantifying integrated proteomic responses to iron stress in the globally important marine diazotroph Trichodesmium. PLoS ONE. 2015;10:1-24.

40. Castruita M, Saito M, Schottel PC, Elmegreen LA, Myneni S, Stiefel El, et al. Overexpression and characterization of an iron storage and DNA-binding Dps protein from Trichodesmium erythraeum. Appl. Environ. Microbiol. 2006;72:2918-24.

41. Walworth NG, Hutchins DA, Dolzhenko E, Lee MD, Fu F, Smith AD, et al. Biogeographic conservation of the cytosine epigenome in the globally important marine, nitrogen-fixing cyanobacterium Trichodesmium. App Environ Microbiol. 2017;19:4700-13.

42. Saito MA, Bertrand EM, Dutkiewicz S, Bulygin VV, Moran DM, Monteiro FM, et al. Iron conservation by reduction of metalloenzyme inventories in the marine diazotroph Crocosphaera watsonii. Proc Natl Acad Sci USA 2011;108:2184-9.

43. Gledhill M, Basu S, Shaked Y. Metallophores associated with: Trichodesmium erythraeum colonies from the Gulf of Aqaba. Metallomics. 2019;11:1547-57.

44. Roe KL, Barbeau K, Mann EL, Haygood MG. Acquisition of iron by Trichodesmium and associated bacteria in culture. Environ Microbiol. 2012;14:1681-95.

45. Bosello M, Zeyadi M, Kraas FI, Linne U, Xie X, Marahiel MA. Structural characterization of the heterobactin siderophores from rhodococcus erythropolis PR4 and elucidation of their biosynthetic machinery. J. Nat Prod. 2013;76:2282-90.

46. Eichner $\mathrm{M}$, Thoms $\mathrm{S}$, Rost $\mathrm{B}$, Mohr W, Ahmerkamp S, Ploug $\mathrm{H}$, et al. $\mathrm{N}_{2}$ fixation in free-floating filaments of Trichodesmium is higher than in transiently suboxic colony microenvironments. New Phytol. 2019;222:852-63.

47. Ho T-Y. Nickel limitation of nitrogen fixation in Trichodesmium. Limnol Oceanogr. 2013;58:112-20.

48. Rose AL. The influence of reactive oxygen species on local redox conditions in oxygenated natural waters. Front Earth Sci. 2016;4:1-11.

49. Liochev SI, Fridovich I. Superoxide and iron: partners in crime. IUBMB Life. 1999;48:157-61.

50. Hansel CM, Buchwald C, Diaz JM, Ossolinski JE, Dyhrman ST, Van Mooy BAS, et al. Dynamics of extracellular superoxide production by Trichodesmium colonies from the Sargasso Sea. Limnol Oceanogr. 2016;61:1188-1200.

51. Korshunov SS, Imlay JA. A potential role for periplasmic superoxide dismutase in blocking the penetration of external superoxide into the cytosol of Gramnegative bacteria. Mol Microbiol. 2002;43:95-106.

52. Kranzler C, Lis H, Finkel OM, Schmetterer G, Shaked $Y$, Keren N. Coordinated transporter activity shapes high-affinity iron acquisition in cyanobacteria. ISME J. 2014;8:409-17.

53. Leventhal GE, Ackermann M, Schiessl KT. Why microbes secrete molecules to modify their environment: The case of iron-chelating siderophores. J R Soc Interface. 2019;16:20180674. https://doi.org/10.1098/rsif.2018.0674.

54. Linhartová I, Bumba L, Mašín J, Basler M, Osička R, Kamanová J, et al. RTX proteins: a highly diverse family secreted by a common mechanism. FEMS Microbiol Rev. 2010:34:1076-112.

55. Held NA, Mcllvin MR, Moran DM, Laub MT, Saito MA. Unique patterns and biogeochemical relevance of two-component sensing in marine bacteria. mSystems. 2019;4:e00317-18. https://doi.org/10.1128/mSystems.00317-18.

56. Mann EL, Ahlgren N, Moffett JW, Chisholm SW. Copper toxicity and cyanobacteria ecology in the Sargasso Sea. Limnol Oceanogr. 2002;47:976-88.

57. Giachino A, Waldron KJ. Copper tolerance in bacteria requires the activation of multiple accessory pathways. Mol. Microbiol. 2020;1-14. https://doi.org/10.1111/ mmi.14522.

58. Romans KM, Carpenter EJ, Bergman B. Buoyancy regulation in the colonial diazotrophic cyanobacterium Trichodesmium Tenue: ultrastructure and storage of carbohydrate, polyphosphate, and nitrogen. J Phycol. 1994;30:935-42.

59. Villareal TA, Carpenter EJ. Diel buoyancy regulation in the marine diazotrophic cyanobacterium Trichodesmium thiebautii. Limnol Oceanogr. 1990;35:1832-1837.

60. Moore K, Doney SC, Lindsay K, Mahowald N, Michaels Anthony F AF. Nitrogen fixation amplifies the ocean biogeochemical response to decadal timescale 
variations in mineral dust deposition. Tellus Ser. B Chem. Phys. Meteorol. 2006;58:560-72

61. Saito MA, Mcllvin MR, Moran DM, Goepfert TJ, DiTullio GR, Post AF, et al. Multiple nutrient stresses at intersecting Pacific Ocean biomes detected by protein biomarkers. Science. 2014;345:1173-7.

62. Lu X, Zhu H. Tube-gel digestion: a novel proteomic approach for high throughput analysis of membrane proteins. Mol Cell Proteomics. 2005;4:1948-58.

63. Perez-Riverol Y, Csordas A, Bai J, Bernal-Llinares M, Hewapathirana S, Kundu DJ, et al. The PRIDE database and related tools and resources in 2019: Improving support for quantification data. Nucleic Acids Res. 2019;47:D442-D450.

64. Timmins-Schiffman E, May DH, Mikan M, Riffle M, Frazar C, Harvey HR, et al. Critical decisions in metaproteomics: Achieving high confidence protein annotations in a sea of unknowns. ISME J. 2017;11:309-14.

65. Saito MA, Bertrand EM, Duffy ME, Gaylord DA, Held NA, Hervey WJ, et al. Progress and challenges in ocean metaproteomics and proposed best practices for data sharing. J Proteome Res. 2019;18:1461-76.

66. Webb SM. The microAnalysis toolkit: X-ray fluorescence image processing software. AIP Confer Proc. 2010;1365:196-199.

67. Webb SM. SIXPack a graphical user interface for XAS analysis using IFEFFIT. Phys. Scr. 2005:1011. https://doi.org/10.1238/physica.topical.115a01011.

68. Grabb KC, Buchwald C, Hansel CM, Wankel SD. A dual nitrite isotopic investigation of chemodenitrification by mineral-associated $\mathrm{Fe}(\mathrm{II})$ and its production of nitrous oxide. Geochim Cosmochim Acta. 2017;196:388-402.

69. Newville M. EXAFS analysis using FEFF and FEFFIT. J Synchr Rad. 2001;8:96-100

70. Hansel CM, Benner SG, Neiss J, Dohnalkova A, Kukkadapu RK, Fendorf S. Secondary mineralization pathways induced by dissimilatory iron reduction of ferrihydrite under advective flow. Geochim Cosmochim Acta. 2003;67:2977-92.

71. van der Walt S, Schönberger JL, Nunez-Iglesias J, Boulogne F, Warner JD, Yager N et al., The scikit-image contributors. scikit-image: image processing in Python. PeerJ. 2014;2:e453.

72. Lorensen W, Marching HEC. Cubes: a high resolution 3D surface construction algorithm. Comput Graph. 1987;21:163-70.

\section{ACKNOWLEDGEMENTS}

We thank the science team and crew of the AT39-05 (Tricolim) cruise, especially Asa Conover, Jaclyn Saunders, and Michael Mazzotta. Joe Jennings (OSU) performed the macronutrient analysis. This work was supported by NSF Graduate Research Fellowship grant \# 1122274 [NAH], the Gordon and Betty Moore Foundation (grant number 3782 [MAS]) the National Science Foundation (grant numbers OCE 1657766, 1850719, 1924554 [MAS] and OCE 1657757 [DAH, EAW]), National Institute of Health (R01GM135709), the Woods Hole Oceanographic Institution Ocean Ventures Fund [NAH] and the Simons Foundation (grant 544236 to NRC). Use of the Stanford Synchrotron Radiation Lightsource, SLAC National Accelerator Laboratory, is supported by the U.S. Department of Energy, Office of Science, Office of Basic Energy Sciences under Contract No. DE-AC02-76SF00515. Figure 4 was created with BioRender.

\section{AUTHOR CONTRIBUTIONS}

$\mathrm{NAH}, \mathrm{MRM}$, JBW and MAS conceptualized the study. NAH and MRM performed proteomic analyses. KMS and $\mathrm{CMH}$ performed synchrotron-based analyses. NRC performed trace metal and assisted with phosphate analyses. AJD performed image analyses. EAW and DAH lead the Tricolim field expedition. NAH and MAS wrote the paper with input from all authors.

\section{COMPETING INTERESTS}

The authors declare no competing interests.

\section{ADDITIONAL INFORMATION}

Supplementary information The online version contains supplementary material available at https://doi.org/10.1038/s43705-021-00034-y.

Correspondence and requests for materials should be addressed to M.A.S.

Reprints and permission information is available at http://www.nature.com/ reprints

Publisher's note Springer Nature remains neutral with regard to jurisdictional claims in published maps and institutional affiliations.

(i) Open Access This article is licensed under a Creative Commons adaptation, distribution and reproduction in any medium or format, as long as you give appropriate credit to the original author(s) and the source, provide a link to the Creative Commons license, and indicate if changes were made. The images or other third party material in this article are included in the articleâ $€^{\mathrm{TM}} \mathrm{s}$ Creative Commons license, unless indicated otherwise in a credit line to the material. If material is not included in the articleâ $\epsilon^{\mathrm{TM}} \mathrm{s}$ Creative Commons license and your intended use is not permitted by statutory regulation or exceeds the permitted use, you will need to obtain permission directly from the copyright holder. To view a copy of this license, visit http:// creativecommons.org/licenses/by/4.0/.

(c) The Author(s) 2021 